\section{Paleoclimatic implications}

The alternating wet and dry phases during the last $3 \mathrm{Ma}$ correlate with numerous other humidity paleoclimate indicators in East Africa, such as mammal assemblages, fossil forest leaves, wood and pollen, as well as with Mediterranean sapropels and dust. The most fascinating phenomenon in this context is the anti-correlation between the East African lake levels and paleoclimate records from subtropical West and Northeast Africa (deMenocal, 1995). In this context, it has been proposed that eolian dust in ocean sediment cores off western and eastern subtropical Africa record environmental changes in Africa that were also thought to represent drier conditions in regions that we studied. However, records from sediment cores off West Africa and Oman may not automatically reflect the nature of East African climate change, since the source areas of these terrigenous deposits are in the Sahara/Sahel regions off West Africa, Arabian peninsula (more than $80 \%$ ) and northeast Africa (less than 20\%), rather than equatorial East Africa where the hominins evolved.

Importantly, the periods of increased humidity, as reconstructed from East African lake levels, correlate both with significant global climatic changes, as well as periods of maximum eccentricity. The period between 2.7 and 2.5 Ma corresponds to the onset of Northern Hemisphere Glaciation, the period between 1.9 and 1.7 Ma corresponds to a significant shift in the Walker Circulation, and the interval between 1.0 and $0.8 \mathrm{Ma}$ corresponds to the initiation of the Mid-Pleistocene Revolution. The phases of high lakelevels in the Ethiopian and Kenyan rifts also correlate with periods of maximum eccentricity, suggesting that changes in local solar radiation are equally important in the moisture history on longer time scales. Since the main effect of eccentricity is to modulate the amplitude of Earth's precession cycles, at times of maximum eccentricity, the seasonality in insolation and, hence, the intensity of the rainy seasons in the tropics increases (Clement et al., 2004). The combination of significant global climate changes with maxima in precessional amplitudes may explain why these humid periods recur only after $0.4 \mathrm{Ma}$, whereas maximum eccentricity and, hence, maximum amplitudes in precession occur at higher periodicities.

These periods of extreme climate variability coincide with key periods of speciation and dispersal of mammals and hominins in East Africa and may have been the cat- alyst for human evolution. In this respect, the close link between lacustrine environments and sites of early hominin occupation is intriguing. Based on these observations, we identify two important issues in mammalian and hominin evolution in East Africa. First, sustained periods of amenable climatic and environmental conditions lasting for protracted periods on the order of $10^{4}-10^{5}$ years, promoting synpatric evolution. Second, lakes may have rapidly appeared and disappeared with precessional cyclicities, producing a rapidly changing mosaic of environments, which ultimately helped promote allopatric evolution.

\footnotetext{
REFERENCES

Clement, A.C., Hall., A. and Broccoli, A.J., 2004: The importance of precessional signals in the tropical climate. Climate Dynamics, 22: 327-341.

deMenocal, P., 1995: Plio-Pleistocene African Climate. Science, 270: 53-59.

Tiercelin, J.J., and Lezzar, K.E., 2002: A 300 million years history of rift lakes in Central and East Africa: an updated broad review. In: Odada, E.O., Olago, D.O. (Eds.), The East African great lakes: limnology, paleolimnology and biodiversity, Kluwer, Dordrecht, pp. 3-60.

Trauth, M.H., Deino, A., Bergner, A.G.N., and Strecker, M.R., 2003: East African climate change and orbital forcing during the last $175 \mathrm{kyr}$ BP. Earth and Planetary Science Letters, 206: 297-313.

Trauth, M.H., Maslin, M.A., Deino, A., and Strecker, M.R., 2005: Late Cenozoic Moisture History of East Africa. Science, 309: 2051-2053.
}

\title{
Surface temperature reconstructions for the last 2000 years
}

\author{
Gerald R. NoRth ${ }^{1}$ and Ian Kraucunas ${ }^{2}$ \\ on behalf of the Committee on Surface Temperature Reconstructions for the Last 2,000 Years, U.S. National Research Council* \\ ${ }^{1}$ Department of Atmospheric Sciences, Texas A\&M University, College Station, USA; g-north@tamu.edu \\ ²Board on Atmospheric Sciences and Climate, National Research Council, Washington, USA; ikraucunas@nas.edu
}

In response to a request from the U.S. Congress, the U.S. National Research Council (NRC) assembled a committee to describe and assess scientific efforts to reconstruct surface temperature records for the Earth over the last 2000 years. This research, and especially the reconstructions originally published by Mann et al. (1998, 1999) and featured in the Intergovernmental Panel on Climate Change
Third Assessment Report (2001), attracted considerable attention because the authors concluded that the Northern Hemisphere was likely warmer during the late 20th century than at any other time during the past millennium. Controversy arose because many people interpreted this result as definitive evidence of anthropogenic causes of recent climate change, while others criticized the methodolo- gies and data that were used. The NRC committee's report (2006) attempts to diffuse this controversy by providing a comprehensive assessment of surface temperature reconstructions for the last 2000 years, as well as the implications of these efforts for our understanding of global climate change. 


\section{Science Highlights: Open Section}

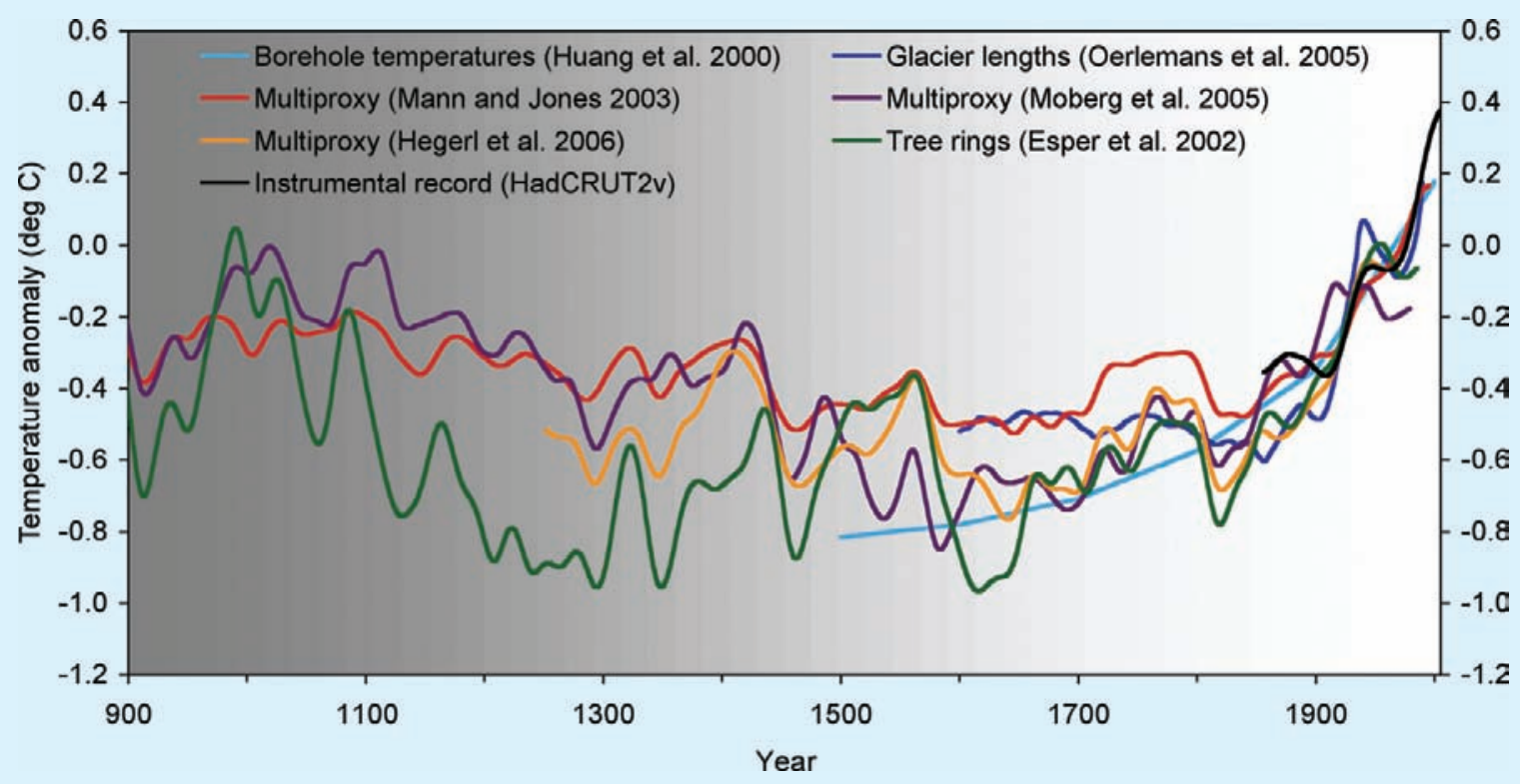

Figure 1: Smoothed reconstructions of large-scale (Northern Hemisphere mean or global mean) surface temperature variations from six different research teams, each using its own methodology and selection of proxies, are shown along with the instrumental record of global mean surface temperature. Each curve portrays a somewhat different history of temperature variations, and is subject to a somewhat different set of uncertainties that generally increase going backward in time (as indicated by the gray shading). This set of reconstructions conveys a qualitatively consistent picture of temperature changes over the last 1100 years, and especially the last 400.

\section{Findings}

After considering all of the available evidence, including the curves shown in Figure 1, the committee reached the following conclusions: (i)The instrumentally measured warming of about $0.6^{\circ} \mathrm{C}$ during the 20th century is also reflected in borehole temperature measurements, the retreat of glaciers, and other observational evidence, and can be simulated with climate models.

(ii)Large-scale surface temperature reconstructions yield a generally consistent picture of temperature trends during the preceding millennium, including relatively warm conditions centered around A.D. 1000 (identified by some as the "Medieval Warm Period") and a relatively cold period (or "Little Ice Age") centered around 1700. The existence and extent of a Little Ice Age from roughly 1500 to 1850 is supported by a wide variety of evidence, including ice cores, tree rings, borehole temperatures, glacier length records, and historical documents. Evidence for regional warmth during medieval times can be found in a diverse but more limited set of records, including ice cores, tree rings, marine sediments, and historical sources from Europe and Asia, but the exact timing and duration of warm periods may have varied from region to region, and the magnitude and geographic extent of the warmth are uncertain.

(iii) It can be said with a high level of confidence that global mean surface temperature was higher during the last few decades of the 20th century than during any comparable period during the preceding four centuries. This statement is justified by the consistency of the evidence from a wide variety of geographically diverse proxies.

(iv) Less confidence can be placed in large-scale surface temperature reconstructions for the period from A.D. 900 to 1600 . Presently available proxy evidence indicates that temperatures at many, but not all, individual locations were higher during the past 25 years than during any period of comparable length since A.D. 900. The uncertainties associated with reconstructing hemispheric mean or global mean temperatures from these data increase substantially backward in time through this period and are not yet fully quantified.

(v) Very little confidence can be assigned to statements concerning the hemispheric mean or global mean surface temperature prior to about A.D. 900 because of sparse data coverage, and because the uncertainties associated with proxy data and the methods used to analyze and combine them are larger than during more recent time periods.

\section{Factors limiting confidence}

The main reason that our confidence in large-scale surface temperature reconstructions is lower before A.D. 1600, and especially before A.D. 900, is the relative scarcity of precisely dated proxy evidence. Other factors limiting our confidence in surface temperature reconstructions include the relatively short length of the instrumental record (which is used to calibrate and validate the reconstructions); the fact that all proxies are influenced by a variety of climate variables; the possibility that the relationship between proxy data and local surface temperatures may have varied 
over time; the lack of agreement as to which methods are most appropriate for calibrating and validating large-scale reconstructions and for selecting the proxy data to include; and the difficulties associated with constructing a global or hemispheric mean temperature estimate using data from a limited number of sites and with varying chronological precision. All of these considerations introduce uncertainties that are difficult to quantify.

\section{Role of reconstructions in climate science}

Overall, the committee found that efforts to reconstruct temperature histories for broad geographic regions using multiproxy methods were an important contribution to climate research and that these large-scale surface temperature reconstructions contain meaningful climatic signals. The individual proxy series used to create these reconstructions generally exhibit strong correlations with local environmental conditions and, in most cases, there is a physical, chemical, or physiological reason why the proxy reflects local temperature variations. Our confidence in the results of these reconstructions becomes stronger when multiple independent lines of evidence point to the same general result, as in the case of the Little Ice Age cooling and the 20th century warming.

Surface temperature reconstructions for periods prior to the industrial era are only one of multiple lines of evidence supporting the conclusion that climatic warming is occurring in response to human activities, and they are not the primary evidence.

Surface temperature reconstructions also provide a useful source of information about the variability and sensitivity of the climate system. To within existing uncertainties, climate model simulations show that the estimated temperature variations during the two millennia prior to the Industrial Revolution can be explained plausibly by estimated variations in solar radiation and volcanic activity during the same period.

\section{Analysis of previous conclusions}

The basic conclusion of Mann et al. (1998, 1999) was that the late 20th century warmth in the Northern Hemisphere was unprecedented during at least the last 1000 years. This conclusion has subsequently been supported by an array of evidence that includes both additional large-scale surface temperature reconstructions and pronounced changes in a variety of local proxy indicators, such as melting on icecaps and the retreat of glaciers around the world, which in many cases appear to be unprecedented during at least the last 2000 years. Not all individual proxy records indicate that the recent warmth is unprecedented, although a larger fraction of geographically diverse sites experienced exceptional warmth during the late 20th century than during any other extended period from A.D. 900 onward.

Based on the analyses presented in the original papers by Mann et al. and this newer supporting evidence, the committee finds it plausible that the Northern Hemisphere was warmer during the last few decades of the 20th century than during any comparable period over the preceding millennium. The substantial uncertainties currently present in the quantitative assessment of large-scale surface temperature changes prior to about A.D. 1600 lower our confidence in this conclusion compared to the high level of confidence we place in the Little Ice Age cooling and 20th century warming. Even less confidence can be placed in the original conclusions by Mann et al. (1999) that "the 1990s are likely the warmest decade, and 1998 the warmest year, in at least a millennium" because the uncertainties inherent in temperature reconstructions for individual years and decades are larger than those for longer time periods, and because not all of the available proxies record temperature information on such short timescales.

\section{Next steps}

Large-scale surface temperature reconstructions have the potential to further improve our knowledge of temperature variations over the last 2000 years, particularly if additional proxy evidence can be identified and obtained from areas where the coverage is relatively sparse, and for time periods before A.D. 1600 and especially before A.D. 900. Furthermore, it would be helpful to update proxy records that were collected decades ago, in order to develop more reliable calibrations with the instrumental record. Improving access to data used in publications would also increase confidence in the results of large-scale surface temperature reconstructions both inside and outside the scientific community. New analytical methods, or more careful use of existing ones, may also help circumvent some of the existing limitations associated with surface temperature reconstructions based on multiple proxies. Finally, because some of the most important potential consequences of climate change are linked to changes in regional circulation patterns, hurricane activity, and the frequency and intensity of droughts and floods, regional and large-scale reconstructions of changes in other climatic variables, such as precipitation, over the last 2000 years would provide a valuable complement to those made for temperature.

\footnotetext{
REFERENCES

Intergovernmental Panel on Climate Change, 2001: Climate Change 2001: The Scientific Basis. Cambridge University Press, Cambridge, UK

Mann, M.E., Bradley, R.S., and Hughes, M.K., 1998. Global-scale temperature patterns and climate forcing over the past 6 six centuries. Nature, 392:779-787.

Mann, M.E., Bradley, R.S., and Hughes, M.K., 1999: Northern Hemisphere Temperatures During the Past Millennium: Inferences, Uncertainties, and Limitations. Geophysical Research Letters, 26(6):759-762.

National Research Council, 2006: Surface Temperature Reconstructions for the Last 2,000 Years. National Academies Press, Washington, D.C.
} 